\title{
Briquette organo-mineral fertilizer based on humic acids
}

\author{
Tatyana Shevchenko ${ }^{1}$, Julia Ustinova ${ }^{1, *}$, Anatoly Popov ${ }^{1}$, Anton Renzyaev ${ }^{1}$ \\ ${ }^{1}$ Kemerovo state University, 6, Krasnaya str., 650000, Kemerovo, Russia
}

\begin{abstract}
The results of research on the creation and use of briquette fertilizers with a high content of humic acids, substances of natural origin, which are naturally compatible multifunctional polyampholites, are presented. In briquette fertilizers, the microbiological binder "Biogum" is used as a binder, which is an organo-mineral fertilizer containing various components. Two variants of briquette fertilizers have been developed: tableted and rod fertilizers, which are necessary for successful cultivation of plants, shrubs, and trees.
\end{abstract}

\section{Introduction}

Humic acids are substances of natural origin, which are naturally compatible multifunctional polyampholites (complexing agents, sorbents, precipitators), which are necessary and therefore quickly absorbed by soils and biota. Humic substances are a natural mixture of complexes of organic compounds that arose during the decomposition of plant and animal residues (humification) [1]. They are found everywhere in soil, sediments, and surface waters and contain hydrophilic and hydrophobic residues that can react with metal ions and hydrophobic organic molecules. All the currently proposed options for interpreting the composition of humic substances have the character of hypothetical flowcharts, for example, presented below (Fig.1).

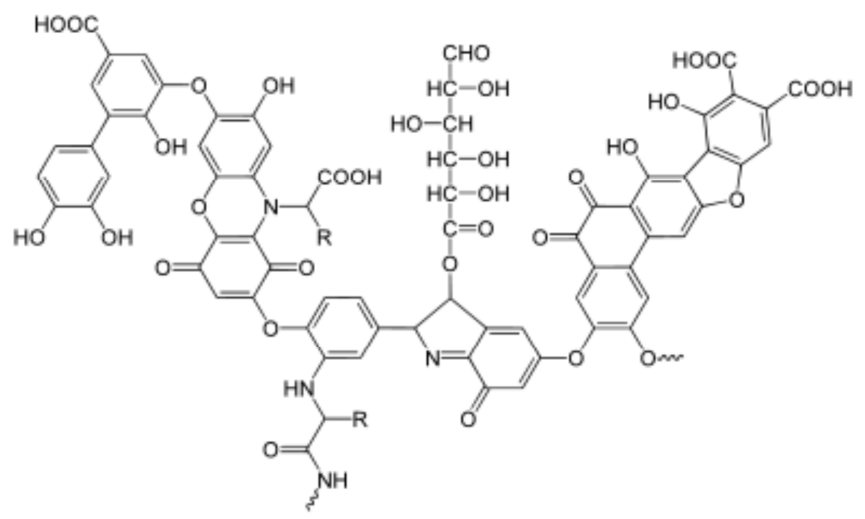

Fig. 1. Example of the molecular structure of ha by Stevenson.

\footnotetext{
*Corresponding author: yul48888048@yandex.ru
} 
From Fig.1 it follows that the nuclei of humic acids are compounds of six-and fivemembered rings, condensed systems that have heterolytically linked nitrogen atoms in their composition.

Humic acids are not a chemically individual substance, but a group of high-molecular chemical compounds with similar composition and properties. Humic acids play various roles in soil chemistry. Humic acids form complexes with ions of various metals, since they have active functional groups (carboxylic and phenolic) [2]. Their complexing ability not only affects the fixation of certain elements in the soil, but also acts as a soil stabilizer, as a source of nutrients and water for plants, as a sorbent for toxic metal ions, radionuclides and organic pollutants.

Possible types of interaction of soil components with humic acids: ion exchange, complexation, oxidation-reduction, donor-acceptor, hydrophobic. In the biosphere, humic substances perform the following additional functions.: 1-accumulative functionaccumulating various chemicals and energy that are then consumed by living organisms. Humic substances have in their composition: 40-60\% carbon; 3-5 \% nitrogen, 20-40\% oxygen, as well as sulfur, phosphorus, hydrogen and ions of various metals. By consuming this type of acid, animals and plants get the necessary elements in the right quantities.2transport function-migration of flows of substances of mineral and organic origin; 3physiological function-increase of productivity of animals and plants, stimulation of their growth, reduction of risk of formation of malignant tumors in animals and birds; 4protective function-binding of heavy metals and toxic substances in hardly soluble and inactive compounds. The high content of humic substances in the soil can completely prevent the entry of toxic substances into groundwater [3].

Humic substances are present mainly in soils and reservoirs. In seawater, their content can be $0.5-3 \mathrm{mg} / 1$, in river water-15-20 mg/l, in swamp water-200-250 mg/l. among soils, the overwhelming number of these compounds is contained in Chernozem [4].

The purpose of this work was to find ways to obtain effective forms of fertilizers containing humic acids.

The most promising direction in the field of fertilizer production is to minimize fertilizers with a universal composition of nutritional components. In developed countries, the use of traditional mineral fertilizers is decreasing and the use of fertilizers containing humic acids is increasing. There are two main forms of application of humic acids - liquid and solid (powders). The liquid form of fertilizers is most common. Briquette technology for the production of fertilizers based on humic acids is not sufficiently developed. Only a few publications on this issue are known $[5,6]$.

In foreign publications, for example, described the core pellets is a highly nutritious fertilizer Japanese production: 1-the flower bar "Katun" on the basis of chicken manure, 2 rod "Aburaya" for coniferous trees on the basis of rapeseed meal, 3-fruits and vegetables web "Guano" from the droppings of waterfowl, 4-universal rod "Kagano" on the basis of crab shell, etc. These drugs prolonged action, easy to use, because we are stuck in the spring or when transplanting plants under root, which allows to conduct effective plant nutrition. The lack of the necessary raw material base does not allow to develop their production [7].

According to the conducted research, fertilizers are offered in the form of coal briquettes. The peculiarity and advantage of using fertilizing coal briquettes is as follows:

- low moisture content, which significantly reduces the weight of the finished product;

- the ability to change the shape, composition and weight of the finished briquette, which eliminates losses during transportation, guarantees accurate weight and takes up less space for storage in utility rooms;

- increased resistance of briquettes when stored in a humid atmosphere. 


\section{Materials and Methods}

It is known that the raw materials for the extraction of humic acids are peat, brown and coal, and sapropel. For conducting experiments, oxidized long-flame coal was selected as a source of humic acids, which is found in large quantities on the territory of Kuzbass as a waste of coal mining and its enrichment. Utilization and processing of oxidized coal is currently the most urgent international problem of coal mining. Therefore, their rational use is an important domestic technological task.

Raw material for briquettes: the coal is oxidized, a binder, additives target.

Coal material: the main raw material for briquettes was finely crushed oxidized coal.

Binder: as a binder, the microbiological binder "Biogum" is used [8, 9] produced according to GOST R 50335-92, according to TU-12-104201-03-92, which is an organomineral fertilizer containing various components with a mass fraction ( $\%)$ : dry matter 50-90; moisture - 65-80; GC-10; P2O5-0.8; K2O-1.0. The density of "Biogum" is $1.07 \mathrm{~g} /$ $\mathrm{cm} 3 ; \mathrm{pH}=-6-7$. It includes a microbiological system adapted to coal, which is active in the presence of moisture in the soil.

The biological components of this drug are strains of the genus Pseudomonas (Pseudomonas denitrificans, Pseudomanas Longa) and the bacteria Acinetobacter calcoaceticus (Fig. 2). (Pseudomonada) - a family of rod-shaped mobile (with polar flagella) asporogenic gram-chemoorganotrophic aerobic bacteria from the order Pseudomonadales. Includes the genera Pseudomonas. The name of the family comes from two Greek roots: "pseudo" - similar and "monas" - the name of a group of protozoa (animals) with polar flagella. Therefore, pseudomonads include both rod-shaped bacteria with a polar flagellum, and slightly bent sticks [10-11].

Target additives used: sawdust, pig manure, chicken manure. The use of such additives can increase the nutritional value of briquette fertilizer and solve some environmental problems of animal husbandry and poultry farming.

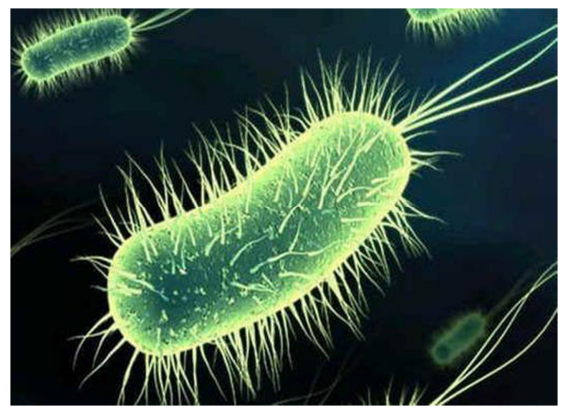

Fig. 2. Appearance of Pseudomonas strains.

\section{Results and Discussion}

The results of a microscopic study of the Acinetobacter calcoaceticus strain of wkpm B4883, colored by gram, CIL-Nielson and Buri-Greens in solutions of a humic preparation are presented in figures 3, 4. Microscopy was performed using an Axio Vert microscope. A1 with X100 magnification. 


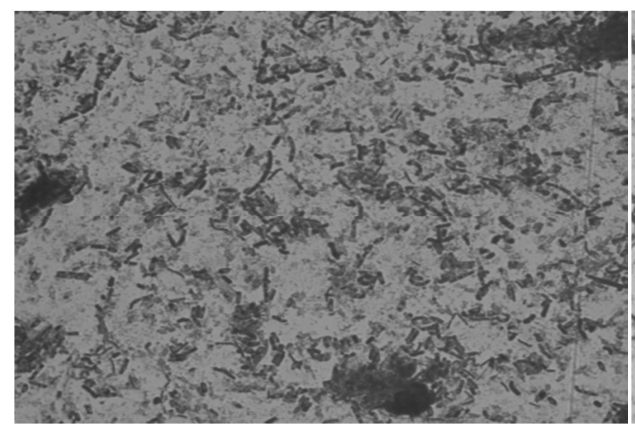

a

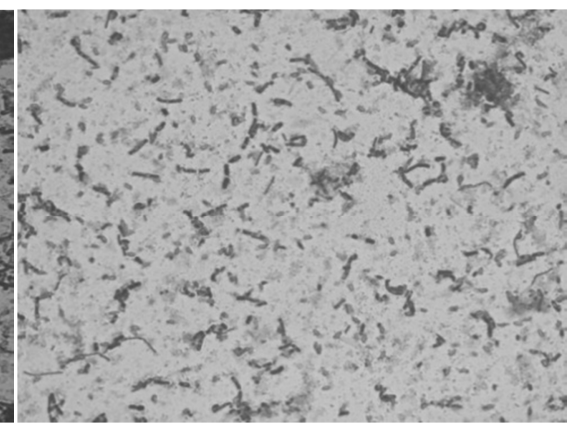

$\mathrm{b}$

Fig. 3. Micrographs of humic preparations of different storage times (a -initial solution, b - after a year of storage).

From the presented drawings, it follows that "Biogum" is a stable microbiological system.

Preparation of fertilizer briquettes in the form of tablets. The General type of product in the form of tablets is shown in Fig. 4.

Briquettes are obtained from finely divided oxidized coal when it is mixed with various components under a pressure of $100 \mathrm{~kg}$ on a stamp press.

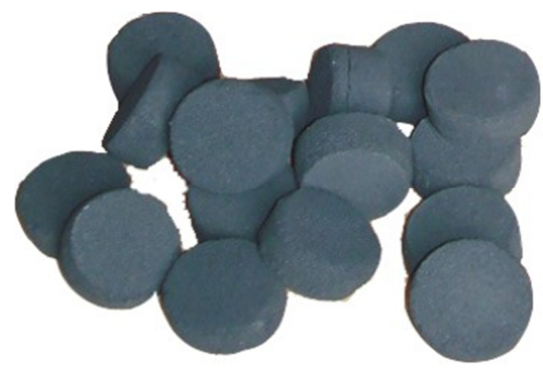

Fig. 4. Organic-mineral briquettes in the form of tablets (diameter $3.5 \mathrm{~cm}$, thickness $2 \mathrm{~cm}$ ).

The selected sizes of briquettes are convenient as a complex fertilizer when transplanting shrubs, trees, vegetable seedlings, and when planting potatoes. The test results and the composition of the obtained complex briquettes are presented in table.1.

Table 1. Composition and strength of composite briquettes.

\begin{tabular}{|c|c|c|c|c|c|c|c|}
\hline № & $\begin{array}{c}\text { Weight of } \\
\text { coal. } \\
\mathbf{g}\end{array}$ & $\begin{array}{c}\text { Weight "Of } \\
\text { Biogum». } \\
\mathbf{g}\end{array}$ & $\begin{array}{c}\text { Weight of } \\
\text { sawdust. }\end{array}$ & $\begin{array}{c}\text { Weight } \\
\text { of } \\
\text { manure. } \\
\mathbf{g}\end{array}$ & $\begin{array}{c}\text { Weight } \\
\text { of } \\
\text { manure. } \\
\mathbf{g}\end{array}$ & $\begin{array}{c}\text { Weight } \\
\text { of } \\
\text { water.g }\end{array}$ & $\begin{array}{c}\text { Strength. } \\
\mathbf{k g} / \mathbf{c m}^{2} \text {. } \\
\mathbf{F}_{\mathbf{1}}\end{array}$ \\
\hline 1 & 80 & 20 & 2.5 & - & - & 30 & 4.1 \\
\hline 2 & 90 & 10 & 2.5 & 5 & - & 30 & 4.4 \\
\hline 3 & 90 & 10 & 2.5 & - & 5 & 30 & 4.6 \\
\hline 4 & 90 & 20 & 2.5 & 5 & 5 & 30 & 4.8 \\
\hline 5 & 90 & 20 & 2.5 & 10 & 5 & 30 & 4.85 \\
\hline 6 & 90 & 20 & 2.5 & 10 & 10 & 30 & 4.9 \\
\hline
\end{tabular}

$* \mathrm{~K}=\mathrm{F}_{1} / \mathrm{F}_{0}$, where $\mathrm{F}_{1}-$ he strength of the briquette on "Biogum" with various additives; $\mathrm{F} 0$-also without additives $\left(3.72 \mathrm{~kg} / \mathrm{cm}^{2}\right), \mathrm{K}$ coefficient of strength.

It follows from table 1 that it is possible to obtain mixed-composition briquettes from waste products of various industries with a sufficiently increased mechanical strength. Determining their ability to Gorenje, as a result of which conclusions were made: 
1. Briquettes based on coal and binder with the addition of sawdust can be used as a fuel briquette.

2. Briquettes based on coal with additives of sawdust, poultry manure and pig manure in different ratios are preferable to use as a briquette fertilizer.

Rod briquettes. We obtained analogs of Japanese samples of rod fertilizers in the form of briquettes with a size of $2 \times 15(\mathrm{~cm})$ in composition from the data of experiment 6 (table.1).

To study the biological activity of the recultivation rod briquettes obtained, three sprouts of tomatoes of the "Persimmon"variety were taken for test samples. As a control sample, the first sprout was taken with soil without enrichment with humic preparation ("Control" - without additives)"). The second sprout was planted in the ground with a reclamation rod consisting of humic preparation and oxidized coal ("Earth + rod").

The third sprout was planted in soil enriched with the solid phase of the humic preparation (a finely divided fertilizer tablet-Fig.5) by mixing in a 1:1 ratio ("Earth + humic preparation").

Test result. The duration of the experiment was 1 month. Control points were determined to track the effect of the humic drug. Table 2 presents the results of experimental determination of the effect of the resulting humic preparation on plant growth and development.

Table 2. Test results of test samples for certain control points (test time).

\begin{tabular}{|c|c|c|c|}
\hline \multirow{2}{*}{$\begin{array}{c}\text { Control } \\
\text { points. day }\end{array}$} & \multicolumn{3}{|c|}{ Results of measurements of the stem length of test samples. cm } \\
\cline { 2 - 4 } & Control & Ground + rod & Earth + humic preparation \\
\hline 0 & 9.6 & 7.4 & 7.5 \\
\hline 10 & 12 & 8.5 & 9 \\
\hline 20 & 14.1 & 16.6 & 18.3 \\
\hline 30 & 31.4 & 30.5 & 30.8 \\
\hline
\end{tabular}

Table 2 and figure 5 show the degree of influence of the humic preparation on the growth and development of stems and leaves of tomatoes of the "Persimmon" variety. From the presented results, it follows that in the control sample the plant height was higher. However, the number of leaves and the degree of branching in the control sample was lower than in samples using briquette fertilizers [12-15].

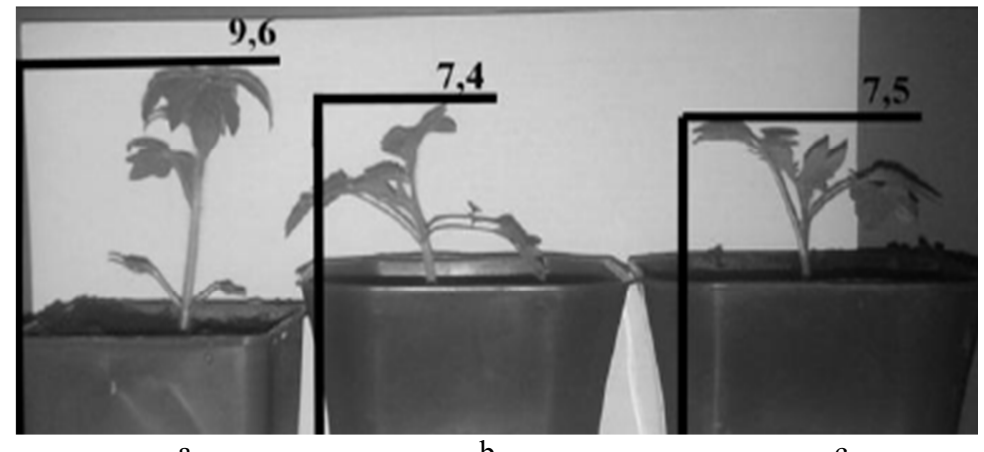

a

b

c 


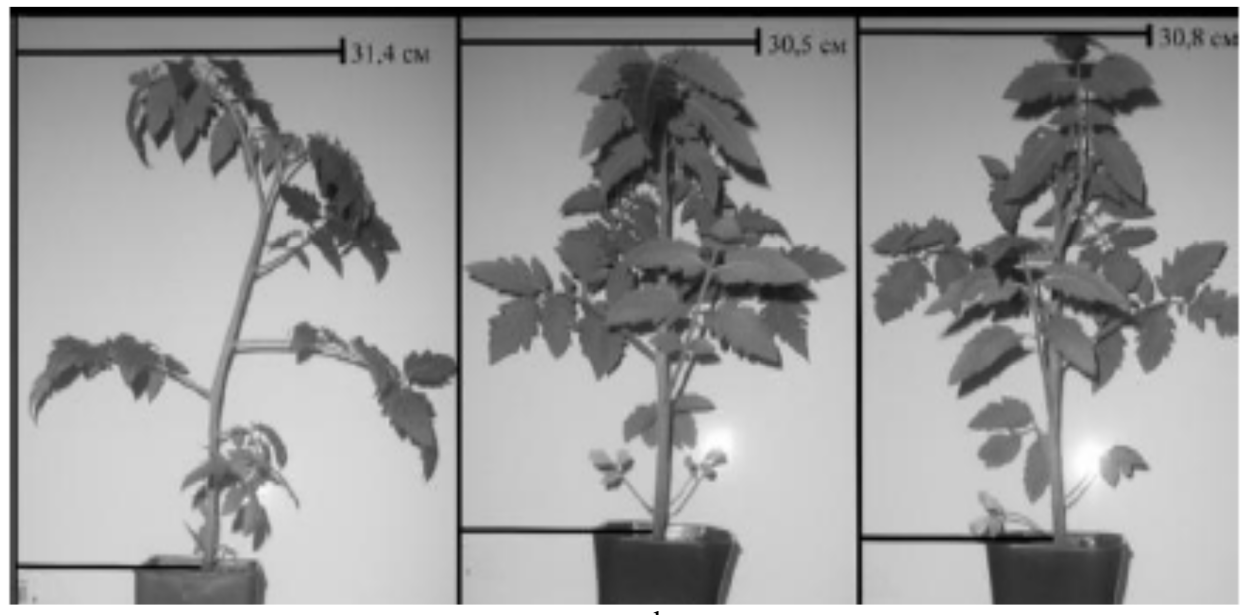

a b
C

Fig. 6. Influence of humic preparation on the growth and development of tomatoes of the "Persimmon" variety»: a - control sample; b - sample " Earth + rod»; c - a sample of "Earth + humic preparation».

Additional full-scale tests were carried out with lawn grass (Fig.7), on the basis of which the influence of briquette fertilizers on the growth of grass plants and the development of their root system was determined. It was found that the grass height was 1.5 times higher when using fertilizers. At the same time, the root system using fertilizers has increased almost 3 times. The presence of a bacterial system in the briquettes increases the overall fertility of the soil.

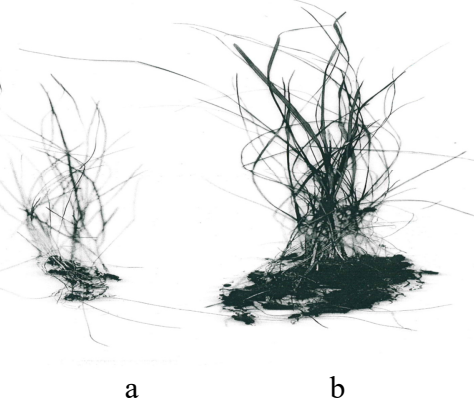

Fig. 7. Root system of lawn grass without additive (a) and with addition (b) of crushed tablet fertilizer.

From Fig.7 it should be noted that the presence of fertilizing plants allows them to increase a significant green mass of stems and leaves. The experiment proved the possibility of organizing accelerated plant growth in the presence of oxidized coal with additives of pig manure, bird droppings and sawdust.

\section{Conclusions}

1. The results of research on the creation and use of briquette fertilizers with a high content of humic acids are presented.

2. Two types of briquette fertilizer are proposed - tableted and rod fertilizer, which is necessary for successful cultivation of plants, shrubs, and trees. 
3.Waste from the coal mining industry-oxidized coal-was used as the source of ha

4. The binding material is the preparation " Biogum ", obtained from oxidized coal and containing humic acids, trace elements and fertility elements $\mathrm{K}, \mathrm{P}, \mathrm{N}$ and a microbiological system adapted to coal materials.

5. The successful geometric shape of the briquette material contributes to its effective use as a fertilizer.

\section{References}

1. A. Rate, A. Mcelnea, R. Bucat, Soil Chemistry (2011) 10.13140/RG.2.1.3069.8326

2. N.O. Aguiar, F.L. Olivares, E.H. Novotny, L.B. Dobbss, L.G. Santos-Júnior, J.G. Chagas, A.R. Façanha, L.P. Canellas, Plant and Soil, The Hague 36(2), 161-174 (2013)

3. Y. Li, F. Fang, J. Wei, et al., Sci. Rep. 9, 12014 (2019) https://doi.org/10.1038/s41598019-48620-4

4. J. Zhang, J. Wang, T. An, D. Wei, F. Chi, B. Zhou, PLoS ONE 12(11), e0186918 (2017) https://doi.org/10.1371/journal.pone.0186918

5. D.P. Dick, A.S. Mangrich, S.M.C. Menezes, B.F. Pereira, Journal of the Brazilian chemical society 13(2), 177-182 (2002)

6. D.C. Olk, P.R. Bloom, M. De Nobili, Y. Chen, D.M. McKnight, M.J. Wells, M.J. Weber, Journal of environmental quality 48, 1633-1643 (2019) doi: 10.2134 / jeq2019. 03.0100

7. M. Asif, P. Naveen, D.C. Panigrahi, S. Kumar, K. Ojha, International Journal of Coal Preparation and Utilization 39(8), 403-420 (2019)

8. M.R.V. Prado, O.L. dos S. Weber, M.F. Moraes, C.L.R. dos Santos, M.S. Tunes, Revista Brasileira de Engenharia Agrícola e Ambiental 20(5), 408-414 (2016)

9. G. Borowski, J. Hycnar, International Journal of Coal Preparation and Utilization 33 (2013) 10.1080/19392699.2013.787993

10. Xiaowei Zhang, Sen Dou, Batande Sinovuyo Ndzelu, Xu Wen Guan, Bo Yan Zhang, Yue Bai, Communications in Soil Science and Plant Analysis 51(1), 107-117 (2020)

11. I.M. Meidel, Solid Fuel Chemistry 48(5), 332-334 (2014) doi: $10.3103 / \mathrm{S} 0361521914050085$

12. M. Paré, S. Allaire, L. Khiari, C. Masso, Le Genie des biosystems au Canada 51, 1-7 (2009)

13. M. Deo, D. De, I. Mani, M. Iquebal, Physical and engineering properties of urea briquettes relevant to design of mechanical applicator, 725-728 (2019)

14. M. Mikos-Szymańska, S. Schab, P. Rusek, et al., Waste Biomass Valor 10, 3673-3685 (2019) https://doi.org/10.1007/s12649-019-00655-4

15. A.M.P. Santos, A.C. Bertoli, A.C.C.P. Borges, R.A.B. Gomes, J.S. Garcia, M.G. Trevisan, Journal of the Brazilian chemical society 29(1), 140-150 (2018) https://doi.org/10.21577/0103-5053.20170122 